
CREST Working Paper

Carrot and Yardstick Regulation:
Enhancing Market Performance
with Output Prizes
Mark Bagnoli
Severin Borenstein
October, 1988
$89-01$





\title{
CARROT AND YARDSTICK REGULATION: ENHANCING MARKET PERFORMANCE WITH OUTPUT PRIZES *
}

\author{
by
}

\author{
Mark Bagnoli \\ Department of Economics \\ University of Michigan
}
and
Severin Borenstein
Department of Economics
.Institute of Public Policy Studies
University of Michigan

\author{
Revised \\ October, 1988
}

- We would like to thank Jim Adams, Larry Blume, Avery Katz, Steve Salant, Ted Snyder, Joe Swierzbinski and Hal Varian for their comments and suggestions. 



\section{Introduction}

Many of the regulatory schemes proposed recently reward a firm for increases in output beyond the level that would be choosen in the absence of government intervention. In this paper, we propose a apparently unrecognized approach to inducing firms to expand output. Output increases are induced when firms compete with one another for a reward (output prize). In a wide variety of circumstances, this scheme induces increases in consumer surplus that exceed the output prize. Thus, consumers/taxpayers can be net beneficiaries and, as a result, might voluntarily agree to such a scheme.

In one sense, the regulation problem was solved by Loeb and Magat [1979] when they described an extremely clever incentive scheme that the government could employ to induce a regulated firm to produce the efficient output even if the government did not know the firm's costs. ${ }^{1}$ In their scheme, the amount that the government pays a firm is set equal to the increase in consumers' surplus that arises as the firm lowers its price and increases its output. In this way, the government makes the firm's revenue function identical to the revenue function of a perfectly price discriminating monopolist and so achieves the Pareto efficient level of output.

Loeb and Magat realized that the scheme had the unsavory property that all of the surplus gains would accrue to the firm. Still, they noted that one could auction the right to be the monopolist and they asserted that the revenues from the auction would equal the profits earned by the monopolist. Unfortunately, in many reasonable cases, the auction is unlikely to capture most of the surplus in the market.

Loeb and Magat's claim will clearly be true when there are at least two identical bidders who have complete information and no bidding costs. In that case, a second price auction results in revenues that are exactly equal to the profits that the monopolist will make under the Loeb-Magat

1 Other similar attempts include Demsetz [1968] and Vogelsang and Finsinger [1979]. 
incentive scheme. Furthermore, if the bidders do not have complete information but the auction is a private values auction ${ }^{2}$ with no bidding costs, the result still follows. In most other situations, however, either it is not known whether the result follows or the result is known to be false.

The easiest way to illustrate this claim is to consider a complete information auction with two heterogeneous bidders and costless bidding. In particular, suppose that the bidders' costs differ. This may be because the firms have different production costs or because one of them is an incumbent who has already paid certain sunk costs that an entrant would have to repcat. If bidder one has the lower costs, then bidder one will win the auction and pay the profits that bidder two would have earned. Since the differential in profits that could be earned might well be large, this auction may capture only a small portion of the profits that the winning bidder will actually earn. Further, even if the differential in profits is small, if there is a cost to bidding, there is only a mixed strategy equilibrium ${ }^{3}$ and so revenues from the auction are still less than asserted by Loeb and Magat.

Things get even murkier when one considers other possibilities. For example, it is clear that the bidders are all going to face similar (identical) demand and so if part of their private information concerns demand, there will be aspects of a common value auction too. In pure common values auctions, English auctions yield the highest revenue because they permit the bidders to infer something about the information of others from their bidding behavior. ${ }^{4}$ Unfortunately, little is known about expected revenues at least in part because the set of equilibrium bidding strategies is not well understood ${ }^{5}$ and less is known about expected revenues in mixed auctions.

2 In a private values auction, one bidder's information about the his own value of the object reveals no information about the value to the other bidders.

3 To see this note that in any pure strategy equilibrium, bidder one must bid arbitrarily more than bidder two. Thus, bidder two must lose the auction with probability one. This means that a better reply would have been not to bid since bidder two would have avoided the bidding costs. This argument can be formalized to show that there is no pure strategy equilibrium.

4 For details, see Milgrom and Weber [1982] or McAfee and McMillan [1987].

s One can characterize a symmetric equilibrium but little is known about the existence or properties of asymmetric equifibria. 
Since the publication of Loeb and Magat's important article, work in this field has emphasized the importance of the relative weighting of consumer and producer benefits. Much of this research has adopted a Principal-Agent framework in which the consumer benefits receive larger weight. In this framework, it is known that if the government's objective function weights the consumers and producers evenly, Loeb-Magat is an optimal incentive scheme. Further, if one believed that the auction scheme could extract all of the profits, then even if one weighted the consumers more heavily, Loeb-Magat with the auction would be an optimal incentive scheme. Nonetheless, many authors have suggested different solutions to this incentive design problem. ${ }^{6}$ The differences arise for two reasons. First, the authors' decide that the weight on the consumer surplus should be higher than the weight on producer profits and second, at least implicitly, that the auction cannot extract all of the producer's profits. Examples include the optimal schemes that are obtained in Baron and Myerson [1982], Sappington [1983] or Baron and Besanko [1984] ${ }^{7}$

Thus, there are two reasons for pursuing the analysis in this paper. First, like many other authors, we believe that the government may want to give greater weight to consumer benefits and that the Loeb and Magat auction scheme will not extract all of the profits. Hence, there is a reason for pursuing alternative methods for controlling firms. Second, the Loeb-Magat scheme requires that the regulator know the market demand curve at least in the region between the monopoly output level and the efficient output level. Without this knowledge, none of the appealing properties of their scheme obtain and so, again, alternatives may well do better. ${ }^{8}$

The alternative that we suggest is to induce competition among firms as a means of inducing output increases. That is, rather than simply "bribing" them ì la a standard incentive scheme that obtains in the Principal-Agent framework, we consider incentive schemes in which the payment to

- That many authors find Loeb-Magat with the auction scheme to be unsatisfactory is clear from the fact that their solutions are not first best, as is Loeb-Magat.

7 An interesting variation is Shleifer [1985] who suggested "yardstick" competition as a method of collecting and utilizing additional information abont the costs and operations of a company.

- For example, if demand becomes extremely convex at prices just below marginal cost and if the government uses a linear approximation to demand in the incentive scheme, then the induced output increase may be far beyond the efficient level. 
one firm can depend on the actions of other firms as well as its own actions. In contrast to Shleifer who used other firms as a means of eliciting useful information, we seek to use other firms to create useful incentives. The firms put additional pressure on one another to produce additional output; the government induces competition between firms that may or may not have been competitors prior to the introduction of the scheme.

More precisely, we study mechanisms in which the government puts up a prize that is divided between the firms in a manner that depends on the output produced by each. ${ }^{9}$ By making the portion of the prize that a firm receives depend on both its own output and the output of the other firms, the government can induce competition for the prize and, as a result, obtain a larger change in output for any total prize. An important feature is that such a scheme can increase consumer surplus by more than the total prize. With simulations, we show that this occurs for a wide range of plausible demand and cost parameters.

We emphasize that the scheme can be implemented by inducing competition between any two (or more) firms-not just between firms that already compete with one another. This means that unrelated public utilities can be "joined" or performance in imperfectly competitive multifirm markets can be enhanced with this scheme. Competition between firms in the product market complicates the analysis, but we show that under reasonable conditions output prizes will still generate Pareto improvements. Our scheme does not yield first-best outcomes, it can, with reasonable demand and cost assumptions, yield large welfare gains and, most distinctively, strict Pareto improvements. In fact, it can do so even when the government has very little information. Thus, it may offer many of the benefits with less institutional (and costly) structure than either yardstick competition or single-firm, principal-agent incentive schemes.

The intuition behind the effectiveness of output prizes comes from recognizing the wide range

9 In contrast to the prizes and incentives (Nalebuff and Stiglitz [1983]) or tournament (Rosen [1986]) literatures, payofis here depend not on the participants' ordinal rankings, but on their actual performance relative to the performance of the others. 
of Pareto improving payments that could be made to a monopolist as a reward for expanding output. Any payment for an additional unit that is greater than the difference between marginal cost and marginal revenue will induce an increase in output and decrease in price. Any payment less than the associated gain in consumer surplus will still leave consumers better off. The government, which is designing an incentive compatible reward system and is interested in maximizing consumer welfare, would like to make marginal payments to the monopolist as close as possible to the firm's lost profits from output expansion $(M C-M R)$. Firm's are unlikely to truthfully reveal the lost profits, but they will compete for additional revenues so long as the marginal reward - the increased share of the prize - is greater than the marginal lost profits.

Since we assume that consumers must put up the funds for the output prize, their welfare will be maximized when the government chooses the prize so that a marginal increase results in an equal increase in consumer surplus. Though the cost and distortion from collecting the funds for the prize is not our immediate concern, it is an important issue in any discussion of a regulatory scheme that involves payments to the firms. There are two approaches to this problem. The first is to assume that the free rider problem is so severe that the government should do the provision. Adopting such a view means that collecting the money is costly since lump sum taxation is infeasible. The second approach is to have the local public good provided privately. There is a growing literature in this area and a lack of consensus. However, Bagnoli and Lipman [1988] have shown that there is a natural contribution game that has the property that every refined equilibrium is in the core. This means that if we were to use this mechanism, then the consumers would voluntarily contribute the amount of money needed to implement the regulatory scheme. Thus, there would be no deadweight social cost to raising the funds (aside from whatever transactions costs exist).

The next section presents the model and our analysis as well as the special cases of independent demands and homogeneous products. Section 3 provides the simulation results alluded to above. Our purpose is to show that the scheme works for a wide range of cost and demand parameters and to provide additional comparative statics results that are the preliminaries to solving for the 
optimal scheme of this type. Section 4 contains concluding comments.

\section{The Model}

Any model of government intervention in the market must specify both the information available to the government as well as the constraints on its ability to intervene. We model the government as having less information than firms and we assume that the government must choose a method of intervention that is made known to firms prior to the time that the firms must respond. That is, the government must "move first" and this move is made without the benefit of full information. This immediately implies that schemes that rely on the government knowing the full information, socially optimal allocation are not feasible. Further, the types of schemes that are possible will depend on the amount of information that the government has. ${ }^{10}$

We assume that the government has no information on production costs and very limited information on demand. In particular, all that is known is the price and quantity sold prior to government intervention. As for the firms, in order to simplify the analysis, we assume that when they make their production decisions, they know their own costs as well as the costs of their rivals, the demand for their product and the scheme that the government has selected. That is, they compete in a complete information game. This is where our simplification helps in the analysis. Since our focus is on how promoting competition through regulation leads to better outcomes, we must solve the game between the firms that the government has induced. Assuming that the firms have complete information is strong, but informational asymmetries between the firms is not our focus and the assumption greatly simplifies the analysis. Relaxing this assumption is possible at the cost of much more complex notation but is straightforward and yields little additional insight.

10 For example, in their classic paper, Loeb and Magat require that the government know the relevant portion of the market demand curve so that the "bribe" of the realized consumer surplus from an output increase can be made. In the principal-agent style model of regulation, it is generally assumed that the government knows all but the regulated firm's costs of production. 
Having informally explained why our model is constructed as it is, let us proceed to a careful description and an analysis of it. We begin by assuming that there are only two firms that the government might regulate. None of our results depend on this restriction, but it greatly simplifies notation. We do not assume that the firms sell the same product or in fact that they sell competing products. Below, we consider two special cases: first, the two firms are each monopolists in independent markets, and second the firms sell homogeneous goods under Cournot competition.

We assume that the government chooses from the following class of schemes designed to promote competition between the firms. The government chooses an amount of money to be split between the firms, referred to as the prize, and a sharing rule that determines the division of the prize. Letting $S\left(q_{1}, q_{2}, x\right)$ be the amount of money paid to firm 1 under the scheme, we restrict ourselves to $S\left(q_{1}, q_{2}, x\right)=s\left(q_{1}, q_{2}\right) x$. That is, the share of the prize that firm 1 receives depends on the output it and its rival choose but not on the size of the prize. This linearity of $S$ in $x$ would be an important restriction if we were searching for the optimal sharing rule, but the limitation does not hamper our demonstration of the possible effectiveness of these schemes.

We assume that $s$ is increasing in its first argument and decreasing in its second. That is, firm 1 's share rises if its output rises and firm 2's share, $1-s\left(q_{1}, q_{2}\right)$, rises if its output rises. We let $\pi$ represent firm 1's profits in its output market as a function of its sales and the sales of firm 2 , and $\hat{\pi}$ be firm 2's profits. ${ }^{11}$ Thus, under the scheme, firm 1's total payoff is

$$
\mathcal{P}_{1}\left(q_{1}, q_{2}, s, x\right)=\pi\left(q_{1}, q_{2}\right)+s\left(q_{1}, q_{2}\right) x
$$

and firm 2's payoff is

$$
\mathcal{P}_{2}\left(q_{1}, q_{2}, s, x\right)=\hat{\pi}\left(q_{1}, q_{2}\right)+\left[1-s\left(q_{1}, q_{2}\right)\right] x
$$

Since $s$ and $x$ are under the regulator's control, if we were to make assumptions about the concavity of the payoff functions, we would be implicitly imposing restrictions on the regulator's set

11 The extreme cases of independent demands and homogeneous products are special cases. For independent demands, firm i's profits do not depend on $j$ 's output and in the homogeneous product case, firm i's profits depend on his own output and on the sum of the outputs. 
of feasible schemes. As we would not be sure of how our results would depend on the restrictions, we choose to make assumptions about the firms' profit functions only. In particular, we assume that each firm's profit function is strictly concave in its own output for each output choice of its rival and we will generally assume that the firm's profits are non-increasing in its rival's output. That is we will not have the firms selling complementary products.

In order to do the comparative statics, we assume that $s$ and the firms' profit functions are twice continuously differentiable. To sign the comparative statics, we will end up assuming that a firm's payoff responds more to a change in its own output than to a change in its rival's, i.e., direct effects outweigh indirect effects. ${ }^{12}$

These assumptions guarantee that there is a Nash equilibrium in the game induced by the government's choice. Further, if $s$ is strictly concave in $q_{1}$ and strictly convex in $q_{2}$, then there is a pure strategy Nash equilibrium. It can be characterized as the solution to the appropriate first order conditions. Unfortunately, we cannot guarantee that there is not a mixed strategy equilibrium too, nor can we guarantee that every solution to the first order conditions is a Nash equilibrium. This latter problem arises because we cannot assume that the payoff function is strictly concave in the firm's choice variable. ${ }^{13}$

Differentiating the firms' payoff functions gives the following first and second order conditions:

$$
\frac{\partial P_{1}}{\partial q_{1}}\left(q_{1}, q_{2}, s, x\right)=\pi_{1}+s_{1} x=0
$$

$$
\frac{\partial \mathcal{P}_{2}}{\partial q_{2}}\left(q_{1}, q_{2}, s, x\right)=\hat{\pi}_{1}-s_{2} x=0
$$

12 This assumption will be made explicitly below.

13 We do not choose to but one could restrict the government to $s$ functions that are strictly concave in $q_{1}$ and strictly convex in 92 . Such an assumption guarantees that the firm's payof function is strictly concave in its choice variable. In fact, one can not only satisfy this constraint but can simultaneously satisfy symmetry. That is, there is a class of $s$ functions which are strictly concave in $q_{1}$, strictly convex in $q_{2}$ and satisfy $s\left(q_{1}, q_{2}\right)=1-s\left(q_{2}, q_{1}\right)$. One might wish to satisfy the latter if one felt that if the firms' output quantities were reversed, their shares of the prize should be too. The simulations in section 3 use a symmetric sharing rule. 
and

$$
\frac{\partial^{2} \mathcal{P}_{1}}{\partial q_{1}^{2}}=\pi_{11}+s_{11} x
$$

$$
\frac{\partial^{2} \mathcal{P}_{2}}{\partial q_{2}^{2}}=\hat{\pi}_{22}-s_{22} x
$$

where we follow the standard convention that subscripts refer to the appropriate partial derivative, e.g., $\pi_{1} \equiv \frac{\partial \pi}{\partial q_{1}}$.

Totally differentiating equations (1) and (2) and rearranging yields

$$
\begin{aligned}
& \frac{\partial q_{1}}{\partial x}=\frac{1}{-\left[\pi_{11}+s_{11} x\right]}\left[s_{1}+\left(\pi_{12}+s_{12} x\right) \frac{d q_{2}}{d x}\right], \\
& \frac{\partial q_{2}}{\partial x}=\frac{1}{-\left[\hat{\pi}_{11}-s_{22} x\right]}\left[-s_{2}+\left(\hat{\pi}_{21}-s_{21} x\right) \frac{d q_{1}}{d x}\right] .
\end{aligned}
$$

Given that the first order conditions are evaluated at a global maximum, these equations define how the firms' equilibrium quantities vary with changes in $x$.

Before substituting, we discuss the intuitive meaning of these equations. Satisfying the second order conditions means that the first term in both equations is positive. The second term, the term in brackets, is made up of three pieces. The first is the direct effect on output due to the fact that the firm is being paid to produce more units. It is positive by our assumptions on $s$. The second piece, $\pi_{12}$ or $\hat{\pi}_{21}$, respectively, arises from the possibility that the firms compete with one another in their output markets. If the firms sell substitutes, one expects that this term is negative. That is, if firm 1's rival increases output, firm 2's marginal profits fall. If the firms were in completely independent markets, then this term would be zero.

The third term is the effect due to the government's scheme of fostering competition between the firms. Since $s$ is twice continuously differentiable, $s_{12}=s_{21}$. If both were zero, the marginal payment to firm $i$ would be independent of the quantity chosen by firm $j$ and so the third term 
is the "inducing competition" effect of our scheme. This identification allows one to clearly see the advantage of inducing competition. If the government had not induced competition, the firm's behavior could only be modified by "bribing" it directly. That is, one could have paid the firm for increases in output by making $s$ depend only on the firm's output not on the output choice of its rival. Thus, if $s_{12}$ is positive and if the incentive scheme induces the rival to increase its output, then the incentives to increase output are larger under induced competition by the amount $s_{12}\left(q_{1}, q_{2}\right) \frac{\partial q_{2}}{\partial x}$.

Letting $D_{i}$ stand for the second derivative of firm $i$ 's objective function, substitution yields

$$
\frac{\partial q_{1}}{\partial x}=\frac{1}{D_{1} D_{2}-\left(\pi_{12}+x s_{12}\right)\left(\hat{\pi}_{21}-x s_{21}\right)}\left[s_{1} D_{2}-s_{2}\left(\pi_{12}+x s_{12}\right)\right] .
$$

We seek the sign of this derivative. If it is negative, we know that there is no possibility that the consumers would be willing to pay for the output prize while if it is positive, they might be willing if the increase in consumers' surplus exceeded the cost. To sign the derivative, we study each term separately. If the products are strategic substitutes, ${ }^{14}$ then the first $\operatorname{term} D_{1} D_{2}$ is positive, but the second term is too because it is the product of two negative numbers. Thus, without additional assumptions, the denominator is unsignable.

Note that $D_{1}$ is how firm 1's marginal payoff changes with changes in 1's output while $\pi_{12}+x s_{12}$ is how firm 1's marginal payoff changes with changes in firm 2's output. It seems sensible to assume that the firm's marginal profits respond more to a change in its own output than to a change in its rival's output. That is the direct effect, $\left|D_{1}\right|$, is larger than the indirect effect, $\left|\pi_{12}+x s_{12}\right|$. If one makes this assumption for both firms, the first term in equation (5) is positive.

The second term is unsignable except in certain special cases that we discuss below or under a much stronger assumption. If we continue to assume that the direct effect outweighs the indirect effect, then the numerator can be shown to be positive if $s$ is symmetric and the firms compete

14 See Bulow, Geanakoplos and Klemperer [1985]. 
symmetrically. For $s$ to be symmetric, we require that if we interchange the quantities produced, the fractions of the prize received are also interchanged. ${ }^{13}$ By having the firms compete symmetrically, we mean that $\pi_{12}\left(q_{1}, q_{2}, s, x\right)+x s_{12}\left(q_{1}, q_{2}\right)=\hbar_{21}\left(q_{1}, q_{2}, s, x\right)-x s_{21}\left(q_{1}, q_{2}\right)$. This is a very strong assumption, however, so we instead analyze the effects in two special cases - independent demands faced by separate monopolists and Cournot competition among producers of a homogeneous product. In the next section, we use simulations to better understand the possibilities for (5) to be positive.

Before turning to the special cases, we must still determine whether or not the change in $x$ induces a larger change in consumer surplus. If it does not, then the consumers would be opposed to the scheme. This boils down to asking whether the derivative of consumer surplus with respect to a change in $x$ is larger than 1 . If the government does not know the demand curves, then it must choose a method of approximation and do the computations in that manner. If it knows the demand curves, then the computations are as follows. Let the demand for each product be $f\left(q_{1}, q_{2}\right)=p_{1}$ and $g\left(q_{1}, q_{2}\right)=p_{2}$ respectively. Then consumer surplus is the line integral

$$
C S\left(q_{1}, q_{2}, p_{1}, p_{2}\right)=\int_{0}^{q_{1}} f(q, 0) d q+\int_{0}^{q_{2}} g\left(q_{1}, q\right) d q-p_{1} q_{1}-p_{2} q_{2}
$$

Differentiating with respect to $x$ and substituting for $\boldsymbol{p}_{\boldsymbol{i}}$,

$$
\begin{aligned}
\frac{d C S}{d x}=\left[f\left(q_{1}, 0\right)+g\left(q_{1}, q_{2}\right)-g\left(q_{1}, 0\right)-f\left(q_{1}, q_{2}\right)-q_{1} f^{\prime}\left(q_{1}, q_{2}\right)\right] \frac{\partial q_{1}}{\partial x} \\
+\left[g\left(q_{1}, q_{2}\right)-g\left(q_{1}, q_{2}\right)-q_{2} g^{\prime}\left(q_{1}, q_{2}\right)\right] \frac{\partial q_{2}}{\partial x}
\end{aligned}
$$

$$
=\left[f\left(q_{1}, 0\right)+g\left(q_{1}, q_{2}\right)-g\left(q_{1}, 0\right)-f\left(q_{1}, q_{2}\right)-q_{1} f^{\prime}\left(q_{1}, q_{2}\right)\right] \frac{\partial q_{1}}{\partial x}+\left[-q_{2} g^{\prime}\left(q_{1}, q_{2}\right)\right] \frac{\partial q_{2}}{\partial x} .
$$

Since the products ar substitutes, when output increases with output prizes, consumer surplus increases. Still, whether the increase is larger than the total prize is not clear. Yet, if (6) is evaluated at $x=0$, it is clear that a one dollar increase in the prize can lead to an increase in

15 Formally, this means that $s\left(q_{1}, q_{2}\right)=1-s\left(q_{2}, q_{1}\right)$. 
consumer surplus that exceeds one dollar. Since the easiest way to see this is in the simulations, we postpone any further discussion of this point to the next section.

Three points should be made before moving on. First, if the government does not know market demand, it can be approximated using data on prior market outcomes by a linear demand curve, an isoelastic demand curve or some other functional form. Doing so alters the terms the partial derivatives multiply in (6), but is not difficult to implement. Second, we have made minimal assumptions about the markets that the firms service and have made minimal assumptions concerning the equilibrium that characterizes their competition. In particular, we should emphasize that we have not imposed symmetry on the equilibrium. That is, the solution to the first order conditions (equations (1) and (2)) may well be asymmetric and if so, our analysis still follows. Finally, we must point out that without strict concavity of the payoff function, care must be exercised in doing comparative static analysis. For many seemingly reasonable s functions, the firm's payoff function may have two peaks. In such a situation, the equilibrium output choices are not differentiable everywhere and so one must also worry about the standard issues of local versus global optima.

\section{A. Independent Demands}

In this subsection, we assume that the firms' demands are independent and that they were pure monopolists prior to the inducing of competition with an output prize.

In addition to providing a better understanding of the more general problem, the case of independent demands is interesting in its own right. The scheme that we have been studying is designed to provide gains by fostering competition among the firms. The independent demands case might be thought of as the purest case, because no other interaction between the firms clouds the analysis. One example of such an application might be electricity companies in different states or locals. Often they are regulated independently or, if comparisons are made, they are relatively 
informal. Under our proposal, direct competition would be introduced. ${ }^{16}$

A second example was a scheme actually considered by the New York Port Authority. In 1984, they entertained the idea of selling or leasing takeoff and landing "slots" at some of the New York area airports that the Port Authority controls. ${ }^{17} \mathrm{~A}$ slot is the right to have a plane take off or land at a certain time of day. For some reason, the Authority decided that it did not want to make a net profit on the venture, so it proposed rebating the total revenues from the activity to the airlines on a passenger-weighted basis. That is, each firm's share of the total prize would be the same proportion as its share of the total number of passengers carried to or from these airports. The plan was never implemented and we know of no other case in which such output prizes have been considered.

To assume that the demands are independent is to assume that firm i's profits (not payoff) depends only on its own output not on the output of its rival. In this case, all of the cross partial derivatives of profits are zero. Hence, (5) becomes

$$
\frac{\partial q_{1}}{\partial x}=\frac{1}{D_{1} D_{2}+x s_{12} x s_{21}}\left[s_{1} D_{2}-s_{2} x s_{12}\right] \text {. }
$$

Again, relying on the direct effect outweighing the indirect effect, the first term is positive. Since $s_{2}$ is negative the second term is also positive. Further, in this case, the change in consumer surplus is easier to calculate because the change in consumer surplus in market 1 is independent of the output choice in market 2 (except as that choice affects the realized change in $q_{1}$ ). That is,

$$
C S=\int_{0}^{q_{1}} f(q) d q+\int_{0}^{q_{2}} g(q) d q-f\left(q_{1}\right) q_{1}-g\left(q_{2}\right) q_{2} \text {. }
$$

Differentiating yields

$$
\frac{d C S}{d x}=-q_{1} f^{\prime}\left(q_{1}\right) \frac{\partial q_{1}}{\partial x}-q_{2} g^{\prime}\left(q_{2}\right) \frac{\partial q_{2}}{\partial x}
$$

16 Other local astural monopolies might also be addressed in this way, snch as water companies, bus systems, etc.

17 See Borenstein [1988) for an analysis of the efficiency of such slot markets. Guler, Plott and Vuong [1986] has a more complete description of the New York Port Authority proposal and Riordan and Sappington [1987] analyze the general problem of awarding monopoly fraachises. 
or, after substituting for the partial derivatives, and evaluating at $x=0$,

$$
\begin{aligned}
\frac{d C S}{d x} & =-q_{1} f^{\prime}\left(q_{1}\right) \frac{s_{1}}{-\pi_{11}}-q_{2} g^{\prime}\left(q_{2}\right) \frac{-s_{2}}{-\hat{\pi}_{22}} \\
& =\frac{p_{1} s_{1}}{\epsilon_{1}\left(-\pi_{11}\right)}+\frac{p_{2}\left(-s_{2}\right)}{\epsilon_{2}\left(-\hat{\pi}_{22}\right)}
\end{aligned}
$$

where $\epsilon_{i}$ is the elasticity of demand in market $i$. Since $s_{i}$ is a choice variable, it is clear that one can make $\left(6^{\prime}\right)$ greater than 1.

The importance of this special case is now clear. One can induce competition among previously non-competing firms and generate sufficient increases in output to cause consumer surplus to rise by more than the "bribe" needed to induce the competition (at least locally). The reason that we continue to emphasize this comparison is that this means that everyone is strictly better off with the regulation than without. That is, the firms, being profit maximizers, make at least the level of profits they made before the regulation ${ }^{18}$ and the consumers as a group are better off even if they put up the "bribe." Thus, if there is some way to get the consumers to put up the bribe, this type of regulation could be accomplished with minimal difficulty.

\section{B. Homogeneous Products}

The second special case that we consider is that of two firms selling a homogeneous product. In this case, a firm's profits depends on its own output and on the sum of the outputs. We do not assume that the firms have the same costs and therefore will not focus on a symmetric equilibrium.

In this case, let the market demand curve be $p=f\left(q_{1}+q_{2}\right)$. Since the firms sell a homogeneous product, it makes sense to compute the change in total output due to a change in $x$. That is,

$$
\frac{\partial q_{1}}{\partial x}+\frac{\partial q_{2}}{\partial x}=\frac{1}{\Delta}\left[s_{1}\left[-\left(\hat{\pi}_{22}-x s_{22}\right)+\left(\hat{\pi}_{21}-x s_{21}\right)\right]-s_{2}\left[-\left(\pi_{11}+x s_{11}\right)+\left(\pi_{12}+x s_{12}\right)\right]\right],
$$

18 They can always choose to make the monopoly quantity and not "compete" for the prize. In this event, if they receive any of the prize, they are better off and if they do not, they are no worse off. 
where $\Delta=D_{1} D_{2}-\left(\hat{\pi}_{21}-x s_{21}\right)\left(\pi_{12}+x s_{12}\right)>0$. Unlike the general case, assuming that the direct effect outweighs the indirect effect makes the change in total output positive. Note that it is not possible to ensure that both firms increase output because $s_{12}>0$ ensures that $q_{1}$ rises but $s_{21}<0$ ensures that $q_{2}$ rises. Thus, one firm's output must increase but the other's might not.

Computing the change in consumer surplus is also easier under the assumption that the firms sell a homogeneous product. Letting $Q$ be total output,

$$
\frac{d C S(Q)}{d x}=-Q f^{\prime}(Q) \frac{\partial Q}{\partial x}
$$

Since we are assuming that $f^{\prime}<0$, i.e., demand curves slope down, we see that consumer surplus rises. Again, it is possible that the induced change exceeds 1 but not guaranteed. As above, it will depend on the government's choice of $s$. 


\section{Simulating the Effects of Output Prizes}

In this section, we use simulations to further explore the effects of output prizes on consumer surplus and efficiency. The previous section proved that such induced output competition may lead to increases in consumer surplus that are greater than the prizes awarded. Here we impose functional forms and parameter values to investigate net consumer surplus gains that might obtain in real world markets. The simulations are necessary because closed-form solutions to the imposed game do not exist for the functional forms that we investigate. We demonstrate that consumer surplus gains can exceed the output prize under reasonable demand and cost conditions. In addition, we generate some "numerical comparative statics" that indicate the situations in which output prizes are most likely to be effective.

We assume that the rule for firm 1's share of the output prize is ${ }^{19}$

$$
s\left(q_{1}, q_{2}\right)=\frac{q_{1}^{k}}{q_{1}^{k}+q_{2}^{k}}
$$

which is just division according to shares of total output when $k=1$ and becomes winner-take-all as $k \rightarrow \infty$. Thus, $k$ might usefully be interpreted as an index of the degree of competition between the two firms eligible for the prize. As $k$ increase, it becomes more important for each firm to produce a large output relative to the other.

Unfortunately, this function is not concave in $q_{1}$ and can therefore lead to local maxima that are not a firm's global best response. For the constant-elasticity demand curves that we have examined (elasticities of 1.1 to 5.0 ), however, a unique profit maximum is obtained for a wide range

19 It will generally be the case that the rule requires some form of "adding" of the firms' outputs. This is straightforward if the firms produce a homogeneous product. If they do not, then some arbitrary means of scaling the products so that they may be "added" is needed. This scaling is arbitrary since it is part of the sharing rule and need not reflect anything about the consumers' tastes for the two products. For example, if $q_{1}$ is kilowatt hours of electricity and $q_{2}$ is pairs of tennis shoes, one arbitrary scaling rule is to assume that one pair of shoes equals 4 kilowatt hours and convert, asing this metric, one output into the anits of the other. 
of $k$ values, including ones that allow us to demonstrate the possibility of Pareto improvements. ${ }^{20}$

We investigate two polar cases of market competition (as opposed to competition for the output prize) between the two firms that will divide the output prize: independent demands and Cournot competition in a single homogeneous-good market. In the former case, the contest affects each firm only through the marginal incentive to increasing its share of the prize, while in the latter case, the increased output of the second firm in the contest also lowers the first firm's marginal revenue from sales. The results presented employ constant elasticity demand functions over a range of elasticities. Similar results obtain for linear demand functions.

The simulations are designed to mimic the decision process of the government prior to intervening. Thus, the data to which the government has access is assumed to be quite limited. In particular, the government is assumed to observe only the price and quantity sold by each firm. . The results are then calculated for a range of possible demand elasticities and total prizes. We assume that the marginal cost is constant, though the extension to increasing or decreasing marginal cost is straightforward and is discussed briefly in section 4.

\section{A. Independent Demands}

Each firm $i$ faces a demand function

$$
q_{i}=\frac{A_{i}}{p_{i}^{\epsilon_{i}}}
$$

20 We have also inveatigated the sharing rule

$$
s\left(q_{1}, q_{2}\right)=0.5+\frac{1}{k_{2}}\left[\ln \left(k_{1} q_{1}-q_{2}\right)-\ln \left(k_{1} q_{2}-q_{1}\right)\right]
$$

where $k_{1}$ is set so 25 to maximize the marginal return to output expansion while maintaining concavity of the share function over the relevant range of outputs and $k_{2}$ is set $s 0$ as to assure that over the relevant range, neither share is ever negative. The consumer surplus enhancement is greater if negative shares are permitted. Since the rule is implemented $s 0$ that it is concave in the firm's own output and the firm's profit function is concave (by assumption), then the payof function, the sum of profits and share of the prize, is concave in own output and a unique proft maximum is assured. Similar efiects were fonnd with this rule, but the combination of concavity and non-negative shares over the relevant range caused the welfare and consumer surplus enhancement to be less effective. 
where $A_{i}$ is a scale factor, and each firm has constant marginal cost equal to $B_{i}$. Given the $q_{i}$, $p_{i}$, and $\epsilon_{i}$, one can immediately solve for $A_{i}$. Having determined the demand function, there is only one $B_{i}$ that makes the observed point a profit maximum. This is obtained from the usual first-order condition.

When the output prize is introduced, each firm $i$ then has a first order condition for profit maximization

$$
\left(1-1 / \epsilon_{i}\right)\left[\frac{A_{i}}{q_{i}}\right]^{1 / \epsilon_{i}}-B_{i}+\frac{x k q_{i}^{k-1} q_{j}^{k}}{\left(q_{i}^{k}+q_{j}^{k}\right)^{2}}=0
$$

where the subscript $j$ refers to the other firm in the contest. The last term is the marginal incentive due to the output prize. In a pure-strategy Nash equilibrium in quantities, the first-order conditions for each firm are satisfied simultaneously. The simulation program solves for such an equilibrium iteratively.

We begin by discussing results when the firms serve identical (but still separate) markets. ${ }^{21}$ We then analyze asymmetry in the markets served by the two firms. Table 1 presents simulations of the effects of an output prize under alternative demand conditions in the two independent markets. In all cases reflected in table 1 , the two firms start out charging the same price (10) and selling the same quantity (5000).

In the cases presented in table 1, a $\$ 500$ prize is to be divided between two firms according to the formula in equation (7). Even though the prize is just $1 \%$ each firm's total revenues, table 1 demonstrates that the induced competition can prompt output increases of much higher percentages and can increase consumer surplus by much more than the cost of the prize. Furthermore, since profit changes are second order at the original profit maximum, the gain in consumer surplus is done at fairly small cost to the producers; profits increase by an amount nearly as great as the prize.

21 Here, identical means identical under the metric nsed to "add" the outputs of the firms in the definition of our sharing rule. 
Table 1 also indicates that, given the starting prices and quantities, the net consumer surplus gain seems to decrease monotonically as elasticity increases from slightly greater than 1 . Though the lost profits from output expansion are greater when demand is relatively inelastic, firms facing such inelastic demand begin from a point of very high markup. The competition for the output prize invokes larger price cuts in these cases, thus causing larger consumer surplus gains for all inframarginal buyers. This is consistent with equation ( $\left.6^{\prime}\right)$.

One set of simulations may seem to be a narrow basis for support of these inferences, but it is straightforward to show that a single set of symmetric parameters is isomorphic to any other set of symmetric parameters and a wide range of seemingly asymmetric cases, so long as total revenues of the two firms are still equal. Rescaling of the measures of output and the unit of exchange (while still maintaining a common unit of exchange for all goods) allows conversion of any such case into the one presented in table $1 . .^{22}$ In fact, table 1 is a general presentation of all cases in which the firms have equal revenues before output prizes are introduced and the output prize is $1 \%$ of either firm's revenues. Similarly, all asymmetric cases in which the total revenues of two firms are in some given ratio and the output prize is a fixed proportion of each are isomorphic.

Of course, changing the elasticity is a real alteration and cannot covered by simple rescaling. In addition, constant-elasticity demand functions are also not completely general for large output prizes. Still, for small prizes (as a proportion of total firm revenues), some constant elasticity is a good approximation to the demand function, and the range of elasticities simulated are generally thought to be the normal range observed in markets where market power is present.

The effect of changes in the size of the output prize relative to the total revenues also cannot

22 Consider the general case of $p_{1} q_{1}=p_{2} q_{2}$. If $q_{1} \neq 5000$, then redefining the units in which good 1 is measured will change $q_{1}$ by $\alpha_{1}$, the scale parameter (where $\alpha=5000 / q_{1}$ ), and change $p_{1}$ by $1 / \alpha_{1}$. A similar scale parameter $\alpha_{2}$ can be applied to firm 2 if $q_{2} \neq 5000$. This will leave $q_{1}=q_{2}=5000$ and $p_{1}=p_{2}$, but not necessarily equal to 10 . Next rescale the unit of exchange by $10 / p_{1}$, noting that this also rescales the prize. Finally, alter the sharing rule so that the quantities used to establish shares are the rescaled quantities, i.e., replace $q_{1}$ with $\alpha_{1} q_{1}$ and $q_{2}$ with $\alpha_{2} q_{2}$. The result is $p_{1}=p_{2}=10, q_{1}=q_{2}=5000$, and the total prize is in the same ratio to total reveave of each firm as it was before the rescaling. 
be surmised from a single set of prices, quantities, and a prize value. Table 2 presents the marginal output, consumer surplus, and profit changes that obtain from changes in the prize at different ratios of the prize to the total firm revenues. It shows, not surprisingly, that the impact of additions to the prize cause additional consumer and total surplus gains, ${ }^{23}$ but at a decreasing rate. This is to be expected since the marginal lost profit from output increases gets larger as each firm expands output from its profit maximizing quantity. The result can be interpreted in two ways. First, for a given size of markets (as measured by total revenues), larger prizes will yield decreasing marginal gains in consumer surplus. Second, for a given size prize, the surplus gain will be greatest when it is applied to larger markets.

When the two firms do not occupy symmetric positions before the output competition is imposed, the results of the game may be more or less favorable than under symmetry. One form of asymmetry that may exist is differences in the firms' total revenues before government intervention. Table 3 shows that for a fixed sharing rule of the type presented in (7), increases in inequality of the firm sizes, holding constant their joint total revenues and the total output prize, leads to smaller total gains in consumer surplus. With the sharing rule used here, each firm's marginal incentive to expand output is greater if the outputs of the two firms are more nearly equal than if they are quite different. A similar result obtains for another type of asymmetry: asymmetric demand elasticities, but equal total revenues before intervention. These results, however, are attributable to the sharing rule employed; the opposite results have obtained with other reasonable sharing rules. ${ }^{24}$ We have not attempted to determine the optimal sharing rules, but it seems likely that asymmetric sizes or price elasticities are likely to be more effectively addressed with asymmetric sharing rules.

These simulation results demonstrate clearly that output prizes can generate net welfare im-

23 This is true over the range presented and is true globally in output and consumer surplus, but total surplus falls with increases in the prize once prices have dropped below margin al coste.

24 In particular, the sharing rule discussed in footnote 20 above shows an increased efficacy when the firms are asymmetric. 
provements for consumers, but they do not by themselves indicate the importance of the competition in obtaining the results. We carry out two comparisons to indicate the role of competition. Table 4 shows the improvements in output enhancement that occur when $k$ is increased in the sharing rule of equation (7). A given prize generates a monotonic increase in output and net consumer surplus as $k$ moves towards, but is still quite distinct from, a winner-take-all division. ${ }^{25}$

The last line of Table 4 presents the results of a linear subsidy that does not depend on the other firm's output and that spends the same total amount of money as the output prize. Though the subsidy was adjusted so as to find the level that would spend a given sum of money, the marginal profit conditions for each firm at the equilibrium shown are calculated on the assumption that each firm believes that the subsidy would be paid on any number of units it were to produce. Interestingly, the linear subsidy does better than the competitive rule when $k<2$ and exactly as well as the rule when $k=2$. This result holds for symmetric cases in which the subsidies to both firms are the same.

The intuition for this result is clear; at the symmetric equilibrium with the competitive rule and $k=2$, each firm's marginal incentive due to the prize is equal to it's average share of the prize per unit on inframarginal units. That is, the last term on the left-hand side of equation (8) is equal to $x / 2 q_{i}$, which is just the linear subsidy rate - and thus the marginal incentive due to a linear subsidy - that would spend a total amount of $x$ while subsidizing $q_{i}$ units from each firm. In general, at a symmetric equilibrium, the marginal incentive due to the sharing rule in (7), the last term on the left-hand side of (8), is $x k / 4 q_{i}$. Thus, so long as a symmetric equilibrium exists, the competitive rule with $k>2$ will yield better results than the linear subsidy.

It is clear from the previous paragraph that the arbitrary choice of rewarding all output above zero does not drive the comparison of the competitive rule and the linear subsidy. Regardless of where the base quantities are set - the differences from which would determine the output

28 Increases in $k$ much beyond those shown in table 4 caused a symmetric equilibrium to fail to exist. 
shares under the competitive rule or would be used to calculate total compensation with a linear subsidy - the competitive rule will be more effective 80 long as $k>2$ and a symmetric equilibrium continues to exist. Both approaches will be more effective if the base quantities are closer to the pre-intervention outputs. The disadvantage, however, of rewarding only changes from the preintervention output (or, more generally, of making base quantities a function of pre-intervention output) is that firm's may then reduce output ex ante in anticipation of such schemes.

Table 4 may also be used to compare the effect of competition for output prizes with a modified version of the Loeb-Magat scheme - one in which the total payment that the government will make to the firms is restricted to be no greater than a given amount. As was pointed out in footnote 8 , if the government were to reward firms under Loeb-Magat by approximating the increase in consumer surplus with a linear demand function, the result could be severe "overshooting;" if the demand function were highly convex, the resulting output could greatly exceed the optimum. A limit on the total payout would then be reasonable.

When $k=4$ in table 4 , the $\$ 500$ output prize yields a gross increase in consumer surplus of $\$ 1961.52$, and a net increase of $\$ 1461.52$. If a payout limit of $\$ 1961.52$ were set under the LoebMagat scheme and if the ex ante auction allowed full recovery of firms' marginal profits due to their scheme, then consumer surplus would increase by the full $\$ 1961.52$. If the auction allowed the government to recover only two-thirds of the change in the firms' profits, however, the firms would be left with about $\$ 654$ and consumer surplus would increase by only about $\$ 1308$. In fact, this competitive scheme with $k=4$ would benefit consumers more than a Loeb-Magat scheme of equal total payout so long as the recovery rate from the prior auction is less than $\mathbf{7 4 . 5 \%}$.

Of course, if the government knew the demand function with some precision, it could use that information under the Loeb-Magat scheme and would have less need to limit the total payout. The same information would not be as useful with competition for output prizes. Still, if the demand function were not well known (or could be discovered only at considerable regulatory expense); or 
if the recovery rate from the auction were quite low, then competition for output prizes could yield a higher expected net benefit to consumers than the Loeb-Magat scheme.

\section{B. Homogeneous Products}

When the firms that compete for shares of an output prize are also direct competitors in the product market, the prize can again have very beneficial results. There is however, a natural limiting process that occurs in which one firm's response to the prize raises the cost to the other firm of also expanding output, because quantity increases by one firm lower both company's marginal revenues. Furthermore, given the price and quantity observations for the two firms and the demand elasticities in the markets in which they operate, the net surplus to be gained by output expansion will be greater if each is a monopolist than if the two are already in a Cournot equilibrium. Thus, both the consumer surplus and total surplus gains from output prizes tend to be smaller when they are used among Cournot competitors than when they are offered to independent monopolists. ${ }^{26}$

Table 5 presents the results from a single set of symmetric price/quantity parameters which, as in the previous section, are isomorphic to any set of symmetric parameters. ${ }^{27}$ As in the independent case, the prize can induce output expansion and gains in consumer surplus that are much greater than the total value of the prize. Also as before, the consumer surplus increase is greater when demand is relatively inelastic.

The most noteworthy difference is that these Cournot competitors can be made worse off by

26 To see this, compare the case in table 5 in which the market demand elasticity is 1.5 and the resulting net consumer surplus gain from a $\mathbf{3 5 0 0}$ prize is $\mathbf{3 9 8 3}$ with the table 1 case in which each firm faces a demand elasticity of 1.5 and the same size prize yields a net consumer surplus increase of $\$ 2435$. Of course, this is largely a result of the different marginal costs implied by the same elasticities at the equilibrium point under monopoly or Cournot competition. When the marginal costs are equalized, by assuming that each of the monopolists faces demand elasticities of 3 - which is the local elasticity that each of the Cournot competitors believes that it faces when the market elasticity is 1.5 and outputs are symmetric - the consumer surplus gain is actually larger in the Cournot market than in the case of independent monopolists.

27 In this case, the translation is trivial since price must be the same and the unit in which the product is measured is common to the two firms. 
the offer of such a prize. Particularly when demand is relatively inelastic, the offer of a prize can lower the equilibrium profits of both firms. Unlike the independent demands case, firms in this situation do not have the option of staying with their pre-prize output and remaining at least as well off as before. The response of the other firm in the contest will lower the profits from any given level of production. Thus, éven at its best response, a firm may earn smaller profits than before the government "giveaway."

The effect of asymmetry, shown in table 7, is similar to the results discussed for independent demands. Greater asymmetry yields smaller consumer surplus gains. ${ }^{28}$ Table 8 corresponds to table 4 for the case of independent demands and again demonstrates the effect of competition between the firms for the prize. The case of $k=2$ is again equivalent in impact to a linear subsidy that has the same total outlay and again these do not benefit consumers nearly as much as rules that employ higher $k$ values, those that migh be characterized as more competitive. In addition, table 8 demonstrates that with less competitive sharing rules $(e . g ., k=2)$, the output prize might improve the welfare of both producers and consumers in a homogeneous good market with Cournot competition.

28 The same caveat as in the last sentence of footnote 25 also applies here as the opposite result obtained with the sharing rule in footnote 20. 


\section{Conclusions}

A wide variety of regulatory schemes that have been proposed reward the firm for increases in output beyond what would be produced in the absence of government intervention. Depending upon the information assumptions and their realism, these schemes may or may not be feasibly implemented. This paper has provided an alternative scheme based on the idea that one means of giving a firm the incentive to increase output is to make it compete with other firms for an output prize. Forcing the firm to compete with others for the prize may allow one to give the firm incentives at a lower cost. An additional benefit of this scheme is that it requires the government to know very little about the environment. The disadvantage is that we can only ensure that the scheme can result in increases in consumer surplus that exceed the output prize but, in general, we cannot achieve the first best outcome.

The other benefit is that the government need not recover profits from the regulated firm to increase consumer surplus. In some of the proposed schemes (such as Loeb and Magat's) the government must recover some of the regulated firm's profits through some type of auction. Since full or substantial recovery of the firm's profits may be difficult in some environments, our proposed approach to intervention may be preferred in some cases. ${ }^{29}$

For reasonable demand and cost parameters, competition for output prizes could result in large total surplus increases and large net consumer surplus increases. In fact, we presented reasonable cases in which the scheme resulted in strict Pareto improvements. In these cases, implementation seems most feasible politically. For the particular rule used in the simulations, forcing otherwise non-competing firms to compete for the output prize and applying the scheme to larger markets with smaller elasticities resulted in larger gains in net consumer surplus. This information can be useful in two ways. First, if one wished to apply the sharing rule studied, this information tells you

29 Recall that it is also true that if the government does not know the relevant portion of the demand curve, the attractive properties of the Loeb-Magat scheme are lost. 
how to get the biggest bang for your buck. Second, the information is a first step in the analysis of optimal schemes that employ our idea.

We view our work as a first step in the process of including induced competition into the set of approaches to government intervention. Two important extensions must be made to complete the analysis of this idea. The first is to study the optimal regulatory mechanism when one is allowed to induce competition between firms. This is a difficult problem but we believe that it is worth pursuing.

Second, the possibility of a dynamic implementation scheme that builds on our idea may be an interesting extension. The reason is that the dynamic structure may give the participating firms additional incentives to expand output and there may be schemes that achieve the first best outcome with these additional incentives. We have considered a couple of possibilities. The basic idea is that the government commits to increase the output prize in the next period if the (approximated) increase in consumer surplus in the current period exceeds the increase in the prize from the previous period to the current one. Such a scheme results in added incentives to increase output as the firms seek to induce the government to increase the output prize. Unfortunately, we have thus far been unable to construct a stopping rule that limits this increase in incentives so that the firms do not exceed the efficient output choices. 


\section{b. References}

Bagnoli, M., and B. Lipman, "Private Provision of Public Goods: Fully Implementing the Core Through Private Contributions," University of Michigan working paper, 1988.

Baron, D., and D. Besanko, "Regulation, Asymmetric Information, and Auditing," Bell Journal of Economics, Autumn 1984.

Baron, D., and R. Myerson, "Regulating a Monopolist with Unknown Costs," Econometrica, July 1982.

Borenstein, S., "On the Efficiency of Competitive Markets for Operating Licenses," Quarterly Journal of Economics, May 1988.

Bulow, J., J. Geanakoplos, and P. Klemperer, "Multimarket Oligopoly: Strategic Substitutes and Complements," Journal of Political Economy, June 1985.

Demsetz, H., "Why Regulate Utilities?," Journal of Law and Economics, February 1968.

Guler, K., C. Plott, and Q. Vuong, "A Study of Zero-out Auctions: Experimental Analysis of a Process of Allocating Private Rights," mimeo, 1986.

Loeb, M., and W. Magat, "A Decentralized Method for Utility Regulation," Journal of Law and Economics, 1979.

McAfee, R.P., and J. McMillan, "Auctions and Bidding," Journal of Economic Literature, June, 1987.

Milgrom, P., and R. Weber, "A Theory of Auctions and Competitive Bidding," Econometrica, September, 1982.

Nalebuff, B., and J. Stiglitz, "Prizes and Incentives: Towards a General Theory of Compensation and Competition," Bell Journal of Economics, Spring 1983.

Riordan, M., and D. Sappington, “Awarding Monopoly Franchises," American Economic Review, September 1987.

Rosen, S., "Prizes and Incentives in Elimination Tournaments," American Economic Review, September 1986.

Sappington, D., "Optimal Regulation of a Multiproduct Monopoly with Unknown Technological Capabilities," Bell Journal of Economics, Autumn 1983.

Shleifer, A., "A Theory of Yardstick Competition," Rand Journal of Economics, Autumn, 1985.

Vogelsang, I., and J. Finsinger, "A Regulatory Adjustment Process for Optimal Pricing By Multiproduct Monopoly Firms," Bell Journal of Economics, Spring 1979.

Williamson, O., "Franchise Bidding for Natural Monopolies-In General and With Respect to CATV," Bell Journal of Economics, Spring 1976. 
TABLE 1

INDEPENDENT DEMANDS

\begin{tabular}{|c|c|c|c|c|c|}
\hline $\begin{array}{l}\text { DEMAND } \\
\text { ELASTICITY } \\
\text { (each mkt) }\end{array}$ & $\begin{array}{l}\text { IMPLIED } \\
\text { MARGINAL } \\
\text { COST }\end{array}$ & $\begin{array}{l}\text { EQUILIB. } \\
\text { PRICE } \\
\text { (each mkt) }\end{array}$ & $\begin{array}{l}\text { EQUILIB. } \\
\text { QUANTITY } \\
\text { (each mkt) }\end{array}$ & $\begin{array}{l}\text { NET CHANGE } \\
\text { IN CONSUMER } \\
\text { SURPLUS } \\
\text { (both mkts) }\end{array}$ & $\begin{array}{l}\text { CHANGE IN } \\
\text { PROFITS } \\
\text { (both firms) }\end{array}$ \\
\hline 1.5 & 3.33 & 9.713 & 5223.37 & 2435.07 & 478.36 \\
\hline 2.0 & 5.00 & 9.808 & 5198.08 & 1461.52 & 480.76 \\
\hline 2.5 & 6.00 & 9.840 & 5205.84 & 1133.41 & 480.04 \\
\hline 3.0 & 6.67 & 9.856 & 5221.78 & 967.84 & 478.56 \\
\hline
\end{tabular}

Results of a $\$ 500$ Output Prize when each firm sets $p=10, q=5000$ before the prize is introduced $(k=4)$.

TABLE 2

INDEPENDENT DEMANDS

\begin{tabular}{|c|c|c|c|c|}
\hline $\begin{array}{l}\text { TOTAL } \\
\text { PRIZE }\end{array}$ & $\begin{array}{l}\text { NET INCREASE IN } \\
\text { CONSUMER SURPLUS } \\
\text { (both markets) }\end{array}$ & $\begin{array}{l}\text { INCREASE IN } \\
\text { PRODUCER PROF ITS } \\
\text { (both markets) }\end{array}$ & $\begin{array}{l}\text { MARGINAL NET } \\
\text { INCREASE IN C.S. } \\
\text { W/ } \$ \text { I PRIZE INCREASE } \\
\text { (both markets) }\end{array}$ & $\begin{array}{l}\text { MARG INAL } \\
\text { PROFIT INCREASE } \\
\text { W/ } 1 \text { PRIZE INC. } \\
\text { (both markets) }\end{array}$ \\
\hline 0 . & 0 . & 0 . & 2.9998 & 0.99992 \\
\hline 100. & 298.41 & 99.21 & 2.9682 & 0.98410 \\
\hline 500 . & 1461.52 & 480.76 & 2.8489 & 0.92442 \\
\hline 1000 . & 2851.65 & 925.82 & 2.7138 & 0.85688 \\
\hline 5000 . & 12082.04 & 3541.02 & 1.9814 & 0.49068 \\
\hline 10000 . & 20622.58 & 5311.29 & 1.4807 & 0.24032 \\
\hline
\end{tabular}

Results of an Output Prize when each market demand elasticity is 2 and each firm has $p=10, q=5000$ before the prize is introduced $(k=4)$. 
TABLE 3

INDEPENDENT DEMANDS -- ASYMMETRIC FIRM SIZES

\begin{tabular}{|c|c|c|c|c|c|}
\hline $\begin{array}{l}\text { QUANTITY } \\
\text { BEFORE } \\
\text { PRIZES }\end{array}$ & $\begin{array}{l}\text { IMPLIED } \\
\text { MARGINAL } \\
\text { COST }\end{array}$ & $\begin{array}{l}\text { EQUILIB. } \\
\text { PRICE }\end{array}$ & $\begin{array}{l}\text { EQUILIB } \\
\text { QUANTITY }\end{array}$ & $\begin{array}{l}\text { GROSS CHANGE } \\
\text { IN CONSUMER } \\
\text { SURPLUS }\end{array}$ & $\begin{array}{l}\text { CHANGE IN } \\
\text { PROF ITS }\end{array}$ \\
\hline $\begin{array}{l}5000 \\
5000\end{array}$ & $\begin{array}{l}5.00 \\
5.00\end{array}$ & $\begin{array}{l}9.8076 \\
9.8076\end{array}$ & $\begin{array}{l}5198.08 \\
5198.08\end{array}$ & $\begin{array}{l}980.76 \\
980.76\end{array}$ & $\begin{array}{l}240.38 \\
240.38\end{array}$ \\
\hline $\begin{array}{l}4000 \\
6000\end{array}$ & $\begin{array}{l}5.00 \\
5.00\end{array}$ & $\begin{array}{l}9.8627 \\
9.9077\end{array}$ & $\begin{array}{l}4112.11 \\
6112.37\end{array}$ & $\begin{array}{l}556.70 \\
559.23\end{array}$ & $\begin{array}{r}81.13 \\
412.39\end{array}$ \\
\hline $\begin{array}{l}3000 \\
7000\end{array}$ & $\begin{array}{l}5.00 \\
5.00\end{array}$ & $\begin{array}{l}9.9575 \\
9.9817\end{array}$ & $\begin{array}{l}3025.66 \\
7025.69\end{array}$ & $\begin{array}{l}128.04 \\
128.36\end{array}$ & $\begin{array}{r}16.35 \\
483.25\end{array}$ \\
\hline $\begin{array}{l}2000 \\
8000\end{array}$ & $\begin{array}{l}5.00 \\
5.00\end{array}$ & $\begin{array}{l}9.9922 \\
9.9981\end{array}$ & $\begin{array}{l}2003.11 \\
8003.11\end{array}$ & $\begin{array}{l}15.56 \\
15.57\end{array}$ & $\begin{array}{r}1.95 \\
498.04\end{array}$ \\
\hline
\end{tabular}

TABLE 4

INDEPENDENT DEMANDS

$\begin{array}{llllcl}\begin{array}{l}\text { K-VALUE } \\ \text { IN SHARING } \\ \text { RULE }\end{array} & \begin{array}{l}\text { IMPLIED } \\ \text { MARGINAL } \\ \text { COST }\end{array} & \begin{array}{l}\text { EQUILIB. } \\ \text { PRICE } \\ \text { (each mkt) }\end{array} & \begin{array}{l}\text { EQUILIB. } \\ \text { QUANTITY } \\ \text { (each mkt) }\end{array} & \begin{array}{l}\text { NET CHANGE } \\ \text { IN CONSUMER } \\ \text { SURUS } \\ \text { (both mkts) }\end{array} & \begin{array}{l}\text { CHANGE IN } \\ \text { PROFIT } \\ \text { (bOth firms) }\end{array} \\ 1.0 & 5.00 & 9.950 & 5049.88 & -2.48 & 498.76 \\ 2.0 & 5.00 & 9.902 & 5099.51 & 490.20 & 495.10 \\ 3.0 & 5.00 & 9.854 & 5148.91 & 978.15 & 489.07 \\ 4.0 & 5.00 & 9.808 & 5198.08 & 1461.52 & 480.76 \\ 5.0 & 5.00 & 9.762 & 5247.02 & 1940.44 & 470.22 \\ 6.0 & 5.00 & 9.717 & 5295.75 & 2415.03 & 457.51\end{array}$

LINEAR SUBSILY THAT SPENDS $\$ 500$

$$
\begin{array}{lllll}
5.00 & 9.902 & 5099.51 & 490.20 & 495.10
\end{array}
$$

Except for linear subsidy case, these are results of a $\$ 500$ Output Prize when demand elasticity in each market is 2 and each firm sets $p=10, q=5000$ before the prize is introduced. 
TABLE 5

HOMOGENEOUS GOODS, COURNOT COMPETITION

$\begin{array}{llllll}\begin{array}{l}\text { DEMAND } \\ \text { ELASTICITY }\end{array} & \begin{array}{l}\text { IMPLIED } \\ \text { MARGINAL } \\ \text { COST }\end{array} & \begin{array}{l}\text { EQUILIB. } \\ \text { PRICE }\end{array} & \begin{array}{l}\text { EQUILIB. } \\ \text { QUANTITY } \\ \text { (eaCh Eirm) }\end{array} & \begin{array}{l}\text { NET CHANGE } \\ \text { IN CONSUMER }\end{array} & \begin{array}{l}\text { CHANGE IN } \\ \text { PROFITS } \\ \text { (bOth E irms) }\end{array} \\ 1.5 & 6.67 & 9.853 & 5112.09 & 983.45 & -252.76 \\ 2.0 & 7.50 & 9.870 & 5132.47 & 816.01 & -170.99 \\ 2.5 & 8.00 & 9.879 & 5154.83 & 731.09 & -130.67 \\ 3.0 & 8.33 & 9.884 & 5177.92 & 679.22 & -106.92\end{array}$

Results of a $\$ 500$ Output Prize when market price is 10 and each firm sets $q=5000$ before the prize is introduced $(K=4)$.

TABLE 6

HOMOGENEOUS GOODS, COURNOT COMPETITION

TOTAL NET INCREASE IN CHANGE IN PRIZE CONSUMER SURPLUS PRODUCER PROFITS (both firms)

\section{MARGINAL NET}

INCREASE IN C.S.

W/\$I PRIZE INCREASE
MARG INAL PROF I T CHANGE W/\$I PRIZE INC. (both firms)

$-0.33336$

$-0.33688$

$-0.35044$

$-0.36628$

$-0.46162$

$-0.53626$

Results of an Output Prize when market denand elasticity is $2, p=10$, and each $\mathrm{firm}$ sets $q=5000$ before the prize is introduced $(K=4)$. 


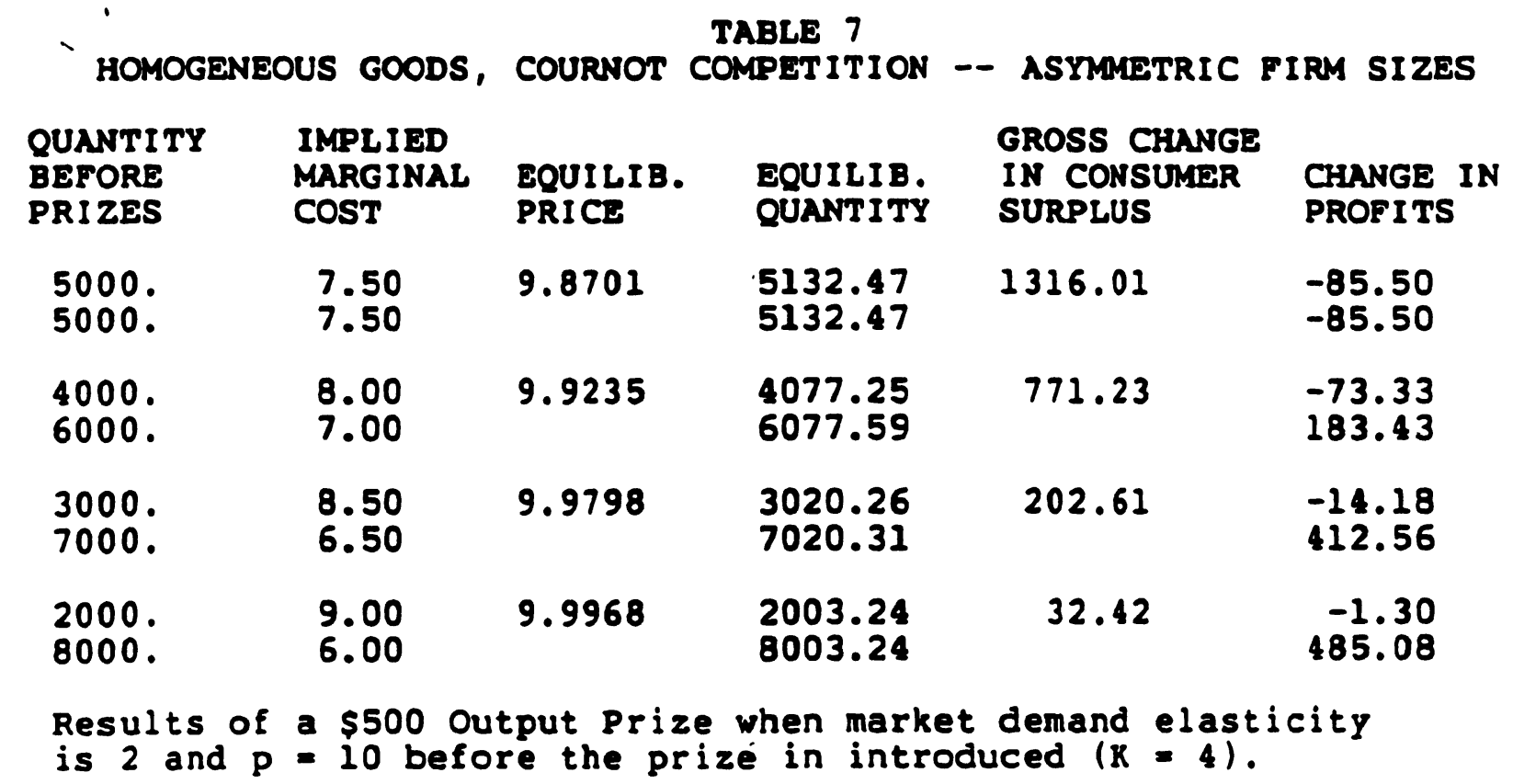

TABLE 8

HOMOGENEOUS GOODS, COURNOT COMPETITION

$\begin{array}{lllccc}\begin{array}{l}\text { K-VALUE } \\ \text { IN SHARING } \\ \text { RULE }\end{array} & \begin{array}{l}\text { IMPLIED } \\ \text { MARGINAL } \\ \text { COST }\end{array} & \begin{array}{l}\text { EQUILIB. } \\ \text { PRICE }\end{array} & \begin{array}{l}\text { EQUILIB. } \\ \text { QUANTITY } \\ \text { (eaCh Eirm) }\end{array} & \begin{array}{l}\text { NET CHANGE } \\ \text { INURPLUS }\end{array} & \begin{array}{l}\text { CONSUMER } \\ \text { PROFIT } \\ \text { (bOth fi Ims) }\end{array} \\ 1.0 & 7.50 & 9.967 & 5033.88 & -168.77 & 333.06 \\ 2.0 & 7.50 & 9.934 & 5066.44 & 162.28 & 165.57 \\ 3.0 & 7.50 & 9.902 & 5099.51 & 490.20 & -2.45 \\ 4.0 & 7.50 & 9.870 & 5132.47 & 816.01 & -171.00 \\ 5.0 & 7.50 & 9.839 & 5165.32 & 1139.78 & -340.06 \\ 6.0 & 7.50 & 9.808 & 5198.08 & 1461.52 & -509.62\end{array}$

LINEAR SUBSIDY THAT SPENDS $\$ 500$

$$
\begin{array}{lllll}
7.50 & 9.934 & 5066.44 & 162.28 & 165.57
\end{array}
$$

Except for linear subsidy case, these are results of a $\$ 500$ Output Prize when market demand elasticity is 2 and each $f$ irm sets $p=10, q=5000$ before the prize is introduced. 



\section{Recent Crest Working Papers}

88 -1: Carol A. Jones, Suzanne Scotchmer, "The Social Cost of Uniform Regulatory Standards in a Hierarchical Government" December, 1987.

88 2: 'Ted Bergstrom, Judy Roberts, Dan Rubinfeld, Perry Shapiro, "A Test for Ffficiency in the Supply of Public Pducation" December 12, 1987.

88 3: Mark Bagnoli, J. Bradley Barbeau, "Competition and Product Line Choice" February, 1988.

88-4: Severin Borenstein, Paul N. Courant, "How to Carve a Medical Degree: Human Capital Assets in Divorce Settlements" December, 1987.

88-5: Mark Bagnoli, Stephen W. Salant, Joseph E. Swierzbinski, "Pacman Refutes the Coase Conjecture: Durable-Goods Monopoly with Discrete Demand" January, 1988.

88-6: Jonathan Cave, Stephen W. Salant, “A Median Choice Theorem" December 29, 1987.

88-7: Mark Bagnoli, Naveen Khanna, "Why Are Buyers Represented by Seller's Agents When Buying a IIouse?" December, 1987.

88 8: Mark Bagnoli, Roger Gordon, Barton L. Lipman, "Takeover Bids, Defensive Stock Repurchases, and the Efficient Allocation of Corporate Control" October, 1987.

88 -9: Mark Bagnoli, Barton L. Lipman, "Private Provision of Public Goods can be Efficient" November, 1987.

88 -10: Michelle J. White, "Urban Commuting Journeys are Not "Wasteful" February, 1988.

88-11: Avery Katz, "A Note on Optimal Contract Damages When Litigation is Costly" February, 1988.

88-12: 'Ted Bergstrom, Jeffrey K. MacKie-Mason, "Notes on Peak Load Pricing" February, 1988.

88-13: Jerry A. Hausman, Jeffrey K. MacKie-Mason, "Price Discrimination and Patent Policy" February, 1988.

89-01: Mark Bagnoli, Severin Borenstein, "Carrot and Yardstick Regulation: Enhancing Market Performance with Output Prizes" October, 1988.

89-02: Ted Bergstrom, Jeffrey K. MacKie-Mason, "Some Simple Analytics of Peak-Load Pricing" October, 1988.

89 -03: Ken Binmore, "Social Contract I: Harsanyi and Rawls" June, 1988.

89 04: Ken Binmore, "Social Contract II: Gauthier and Nash" June, 1988.

89 05: Ken Binmore, "Social Contract III: Evolution and Utilitarianism" June, 1988.

89 06: Ken Binmore, Adam Brandenburger, "Common Knowledge and Game Theory" July, 1988.

89 07: Jeffrey A. Miron, "A Cross Country Comparison of Seasonal Cycles and Business Cycles" November, 1988.

89-08: Jeffrey A. Miron, "The Founding of the Fed and the Destabilization of the Post-1914 Economy" August, 1988.

89 -09: Gerard Gaudet, Stephen W. Salant, "The Profitability of Exogenous Output Contractions: A ComparativeStatic Analysis with Application to Strikes, Mergers and Export Subsidies" July, 1988.

89-10: Gerard Gaudet, Stephen W. Salant, "Uniqueness of Cournot Equilibrium: New Results from Old Methods" August, 1988.

89-11: Hal R. Varian, "Goodness-of-Fit in Demand Analysis" September, 1988.

89-12: Michelle J. White, "Legal Complexity" October, 1988.

89-13: Michelle J. White, "An Empirical Test of the Efficiency of Liability Rules in Accident Law" November, 1988.

89-14: Carl P. Simon, "Some Fine-Tuning for Dominant Diagonal Matrices" July, 1988. 



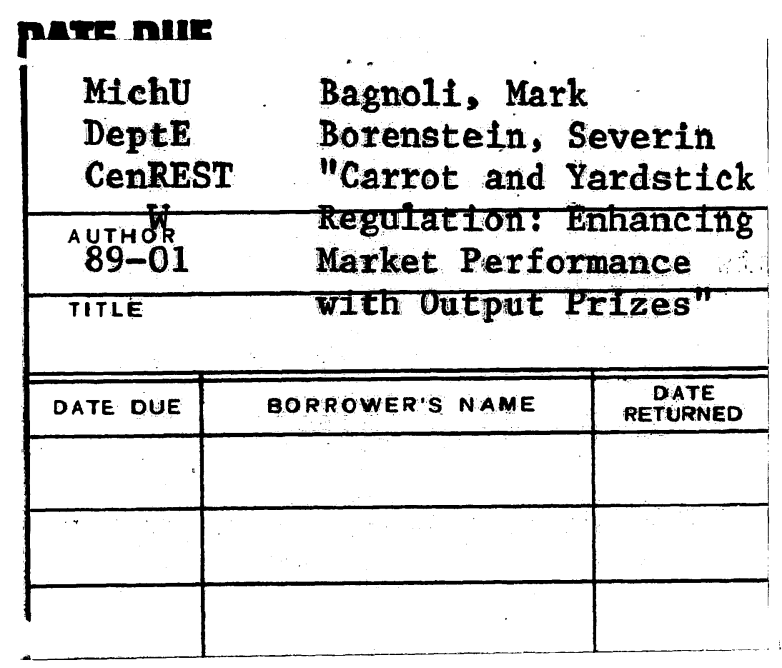


